Dementia and Geriatric Cognitive Disorders
Accepted: October 7, 2009

Published online: December 10, 2009

\title{
Vitamin E Use Is Associated with Improved Survival in an Alzheimer's Disease Cohort
}

\author{
Valory N. Pavlik ${ }^{a}$ Rachelle S. Doody ${ }^{b}$ Susan D. Rountree ${ }^{b}$ Eveleen J. Darby ${ }^{b}$ \\ Departments of a Family and Community Medicine and ${ }^{b}$ Neurology, Baylor College of Medicine, Houston, Tex., USA
}

\section{Key Words}

Alzheimer's disease $\cdot$ Survival $\cdot$ Vitamin E

\begin{abstract}
Background: Vitamin E at a dose of 2,000 IU per day has been shown to delay Alzheimer's disease (AD) progression, but recent studies have questioned the safety of this dose level and the overall efficacy of vitamin $E$ in $A D$ treatment. Methods: We analyzed the survival history of 847 probable or mixed AD patients followed in a research center between 1990 and the censoring date of December 31, 2004. Standard practice during this period was to recommend vitamin $\mathrm{E}$ at 1,000 IU twice daily to all patients. We used Cox proportional hazards modeling to assess the association of vitamin $\mathrm{E}$ alone, or in combination with a cholinesterase inhibitor (ChEl), with all-cause mortality, adjusting for important covariates. Approximately two thirds of the patients took vitamin $\mathrm{E}$ with a $\mathrm{ChEl}, 10 \%$ took vitamin $\mathrm{E}$ alone, and $15 \%$ took no antidementia drug. Results: The adjusted hazard ratio (HR) associated with vitamin $\mathrm{E}$ (with or without a ChEl) was 0.71 (95\% Cl: $0.57-0.89 ; p=0.003$ ). Compared to the no drug treatment group, the HR for vitamin E alone or with another drug was 0.77 (95\% Cl: 0.60-1.0); the HR for ChEl use alone was 1.2 (95\% Cl: 0.87-1.60). Conclusion: The results do not support a concern over increased mortality with high-dose vitamin E supplementation.

Copyright $\odot 2009$ S. Karger AG, Basel
\end{abstract}

○ 2009 S. Karger AG, Basel

Fax +41613061234 E-Mail karger@karger.ch www.karger.com www.karger.com/dem

\section{Background}

Vitamin E ( $\alpha$-tocopherol) is a lipid-soluble vitamin with antioxidant properties which may decrease freeradical-mediated damage in neuronal cells. Many, but not all, observational studies have suggested a protective effect of vitamin $\mathrm{E}$ with or without other antioxidant vitamins for the prevention of cognitive decline and Alzheimer's disease (AD) [1-5]. Because of both laboratoryand population-based data, vitamin $\mathrm{E}$ has been proposed as a treatment to delay neurodegeneration in $\mathrm{AD}$ patients. One randomized clinical trial in moderately severe $\mathrm{AD}$ patients resulted in a significant delay in disease progression (death, institutionalization, loss of activities of daily living, and Clinical Dementia Rating score increase) in patients assigned 2,000 IU/day of vitamin E compared to placebo [6]. However, a trial of 2,000 IU of vitamin E daily had no effect on delaying the progression of $\mathrm{AD}$ in participants with amnestic mild cognitive impairment [7]. Recent meta-analyses of randomized trials involving vitamin $\mathrm{E}$ in cardiac patients and other patient groups suggest a slightly higher mortality risk associated with vitamin E treatment [8-10]. One meta-analysis [9] concluded that the mortality rate associated with vitamin E treatment increased in a nonlinear dose-dependent manner, with the relative risk beginning to rise above 1 at doses $\geq 400$ IU/day. 
The AD and Memory Disorders Center (ADMDC) at the Baylor College of Medicine, Houston, Tex., USA, has served as a referral center for AD diagnosis and treatment for over 20 years. Between 1992 and 2004, standard practice in the Baylor ADMDC was to recommend vitamin $\mathrm{E}$ supplementation at a dose of 1,000 IU 2 times per day to all AD patients, in addition to any other indicated antidementia drugs. Prior to 1992, some patients self-supplemented themselves, although usually at lower doses than 2,000 IU/day. After 2004, patients continued to receive this recommendation and were given an information sheet summarizing the potential benefits and risks reported in the literature. The purpose of this study was to determine if treatment with vitamin $\mathrm{E}$ was associated with higher mortality in the Baylor ADMDC AD cohort.

\section{Patients and Methods}

\section{Subjects}

Patients were eligible for the study if they had agreed to have their clinical data stored in a database approved by the institutional review board at the Baylor College of Medicine, met the criteria for a diagnosis of probable AD based on the NINCDSADRDA (National Institute of Neurological and Communicative Disorders and Stroke and the Alzheimer's Disease and Related Disorders Association) [11], and had at least 1 complete comprehensive annual follow-up evaluation after their initial visit. Patients who presented with significant strokes at baseline or met criteria for probable ischemic vascular dementia (NINDSAIREN, National Institute of Neurological Disorders and Stroke and Association Internationale pour la Recherche et l'Enseignement en Neurosciences) were excluded, even if AD was suspected. However, patients who met NINCDS criteria for probable AD but had cerebrovascular changes (extensive white matter disease or lacunae in noncortical regions), or who developed a stroke after the probable $\mathrm{AD}$ diagnosis, were included in order to examine the impact of concomitant cardiovascular disease (CVD) on survival. All patients underwent an evaluation by a neurologist and completed a standardized dementia workup that has been in continuous use since 1989 [12]. The analysis included all patients in the cohort who met the eligibility criteria through the censoring date of December 31, 2004.

\section{Measures}

The initial visit included a detailed history and interview with the patient and informant, neurological and physical examinations, a neuroimaging study of the brain, neuropsychological testing and screening laboratory studies. The duration of illness was estimated by the physician at the new patient's visit by a standardized procedure reported to the nearest half-year [13]. The initial battery of neuropsychological tests, along with a neurological and physical exam, were repeated annually.

Drugs approved for the treatment of AD first became available in the USA in 1993. The first class of drugs developed for AD consisted of the cholinesterase inhibitors (ChEI) including tacrine (no longer available due to side effects), galantamine, rivastigmine and donepezil. Memantine, a drug that modulates glutamate via $\mathrm{N}$-methyl-D-aspartate receptor antagonism, was approved in 2003 for the treatment of moderate-to-severe AD. Since 1992, the Baylor ADMDC has recommended the use of vitamin $\mathrm{E}$ as a supplement to other antidementia treatment or alone if other treatments are contraindicated. At each visit, the patient's medication history during the interval between visits, including his or her vitamin E use, was recorded on a standardized form and stored in the electronic data base.

Baseline neuropsychological testing included the MMSE (Mini-Mental State Examination) [14], a widely used dementia severity test with scores that range from 0 to 30 points. The description of the full battery of neuropsychological tests used in the ADMDC cohort has been described elsewhere [12].

The vital status of each actively followed patient was updated every 6 months by telephone follow-up and searches of the National Death Index.

\section{Analysis}

Medication exposure during the interval between each patient's visits was represented with indicator variables representing the classes of medications taken by the patient. Thus, for example, any ChEI use since the last visit was coded as 1 , and 0 otherwise. For the survival analysis, a single variable, representing mutually exclusive exposure categories in each interval, was created to reflect the following combinations: no drug use (reference category), vitamin E alone or with another antidementia drug, and ChEI without vitamin E. After 2003, some regimens included memantine. Between 2003 and 2004, the number of patients taking memantine alone was too small to be analyzed as a separate group. Approximately $5 \%$ of the patients classified as taking vitamin $\mathrm{E}$ with or without a ChEI during this period could also have taken memantine.

Time-dependent Cox survival models were constructed to test the effects of the independent medication exposure variables on survival, adjusting for potential confounders including age at diagnosis, sex, race (white or nonwhite), years of education, duration of symptoms, baseline severity of disease based on MMSE score [14] $(20-30=$ mild; $10-19=$ moderate; $0-9=$ severe $)$, and presence of relevant cerebrovascular disease features on imaging.

Two survival models were tested, one in which patients on any regimen that included vitamin $\mathrm{E}$ were compared to those not taking vitamin $\mathrm{E}$ (including patients taking no antidementia drugs), and one in which 3 groups were compared: (1) patients on antidementia drug regimens that included vitamin E; (2) patients on regimens that did not include vitamin $\mathrm{E}$, and (3) a no drug treatment reference group.

\section{Results}

The characteristics of the 847 patients who met the basic inclusion criteria are shown in table 1 . The average age at the baseline visit was $73.5( \pm 8.6)$ years, and $67.3 \%$ of the subjects were female. The severity of the disease at baseline was classified as mild in 52\%, moderate in $36 \%$ 
and severe in $12 \%$ of the cases. The average survival from first ADMDC visit to death was $5.5 \pm 2.8$ years (median survival: 5.0 years). The earliest cohort entry date for the patients included in the analysis was January 2, 1990, and the latest entry date was January 23, 2003.

Drug exposure information on the interval before any given visit could not be determined with certainty in approximately $10 \%$ of the visits. Because of the longitudinal nature of the data, the patients with undetermined drug exposure varied from interval to interval. In table 2, we report the distribution of exposure to each defined category of antidementia drugs (including vitamin E) for the first ADMDC visit, the second ADMDC visit (required for inclusion in the cohort) and the last ADMDC visit. At the first ADMDC visit, $54 \%$ of the patients for whom drug exposure information was available were not taking any antidementia medication, and just over $25 \%$ were taking vitamin $\mathrm{E}$ alone or with a ChEI. By the final visit, $62 \%$ of the patients were taking both vitamin $\mathrm{E}$ and a ChEI, 9\% were taking vitamin $\mathrm{E}$ alone, $13 \%$ were taking a $\mathrm{ChEI}$ without vitamin $\mathrm{E}$, and $16 \%$ were not taking any drug.

Table 1. Patient characteristics

\begin{tabular}{lcr}
\hline Age at first ADMDC visit, years & $73.5 \pm 8.6$ & $43.2-93.9$ \\
Females, $\mathrm{n}$ & $570(67.3 \%)$ & \\
Nonhispanic whites, $\mathrm{n}$ & $741(87.5 \%)$ & \\
Duration of education, years & $13.4 \pm 3.5$ & $0-29$ \\
Duration of symptoms, years & $3.8 \pm 2.5$ & $0.5-20$ \\
Baseline MMSE score & $18.8 \pm 6.8$ & $1-30$ \\
Baseline severity category, $\mathrm{n}$ & & \\
$\quad$ Mild (MMSE $\geq 20)$ & $439(51.8 \%)$ & \\
$\quad$ Moderate (MMSE 10-19) & $309(36.5 \%)$ & \\
$\quad$ Severe (MMSE <10) & $99(11.7 \%)$ & \\
Presence of CVD at baseline, n & $49(5.8 \%)$ & \\
Survival time from first & & \\
$\quad$ ADMDC visit, years & $5.5 \pm 2.8$ & $0.99-14.7$ \\
\hline
\end{tabular}

Values denote means \pm SD or ranges (column 3 ), unless specified otherwise.
In the first Cox survival model (table 3), in which vitamin $\mathrm{E}$ use was compared to no vitamin $\mathrm{E}$ use, vitamin E use was associated with a $29 \%$ reduction in mortality risk (hazard ratio, $\mathrm{HR}=0.71$; 95\% CI: 0.57-0.89; $\mathrm{p}=$ 0.003 ) after adjusting for age, sex, race and the baseline severity of symptoms. Neither education nor the duration of symptoms before the baseline visit nor concurrent cerebrovascular disease was significantly associated with survival.

In the model in which no drug treatment served as the reference group for vitamin $\mathrm{E}$ use (with or without a ChEI) and ChEI use without vitamin E, there was no survival benefit with ChEI use alone (HR $=1.20$; 95\% CI: $0.87-1.65 ; \mathrm{p}=0.273)$, whereas those taking vitamin $\mathrm{E}$ with or without a ChEI had a $23 \%$ lower mortality risk compared to those not taking any drugs $(\mathrm{HR}=0.77 ; 95 \%$ CI: $0.60-1.00 ; \mathrm{p}=0.051$ ).

The survival functions associated with the 3 categories of drug exposure evaluated in model 2 are depicted in figure 1 . The survival curves indicate that the survival advantage associated with vitamin $\mathrm{E}$ use does not become apparent until after 4 or more years of follow-up.

\section{Discussion}

There was no evidence that treatment with high doses of vitamin $\mathrm{E}$ had an adverse effect on survival in an $\mathrm{AD}$ cohort followed up for up to 15 years. In fact, patients whose regimens included vitamin $\mathrm{E}$ tended to survive longer than those taking no drug or a ChEI alone. It is noteworthy that the survival benefit to those taking vitamin E did not become apparent until after 4 or more years of follow-up.

The results of this study do little to resolve the controversies over the benefits and risks of vitamin E supplementation in the prevention or treatment of AD. In spite of significant protective effects seen against cancer, heart disease and dementia in some, but not all, observational studies, randomized clinical trials have generally failed

Table 2. Distribution of drug exposure categories at first, second and last ADMDC visit (n)

\begin{tabular}{|c|c|c|c|c|c|c|c|}
\hline & $\begin{array}{l}\text { Vitamin } \\
\mathrm{E}+\mathrm{ChEI}\end{array}$ & $\begin{array}{l}\text { ChEI without } \\
\text { vitamin E }\end{array}$ & $\begin{array}{l}\text { Vitamin E } \\
\text { alone }\end{array}$ & $\begin{array}{l}\text { No drug } \\
\text { treatment }\end{array}$ & $\begin{array}{l}\text { Total with drug } \\
\text { exposure recorded }\end{array}$ & $\begin{array}{l}\text { Exposure } \\
\text { undetermined }\end{array}$ & $\begin{array}{l}\text { Total patients } \\
\text { in cohort }\end{array}$ \\
\hline First ADMDC visit & $137(18.5 \%)$ & $135(18.2 \%)$ & $67(9.1 \%)$ & $401(54.2 \%)$ & 740 & $104(12.3 \%)$ & 847 \\
\hline Second ADMDC visit & $428(57.5 \%)$ & $121(16.2 \%)$ & $53(7.1 \%)$ & $143(19.2 \%)$ & 745 & $87(10.3 \%)$ & 847 \\
\hline Final ADMDC visit (if >2) & $310(61.9 \%)$ & $65(13.0 \%)$ & $47(9.4 \%)$ & $79(15.8 \%)$ & 501 & $50(9.1 \%)$ & 552 \\
\hline
\end{tabular}


Fig. 1. Survival functions associated with the 3 categories of drug exposure evaluated in model 2.

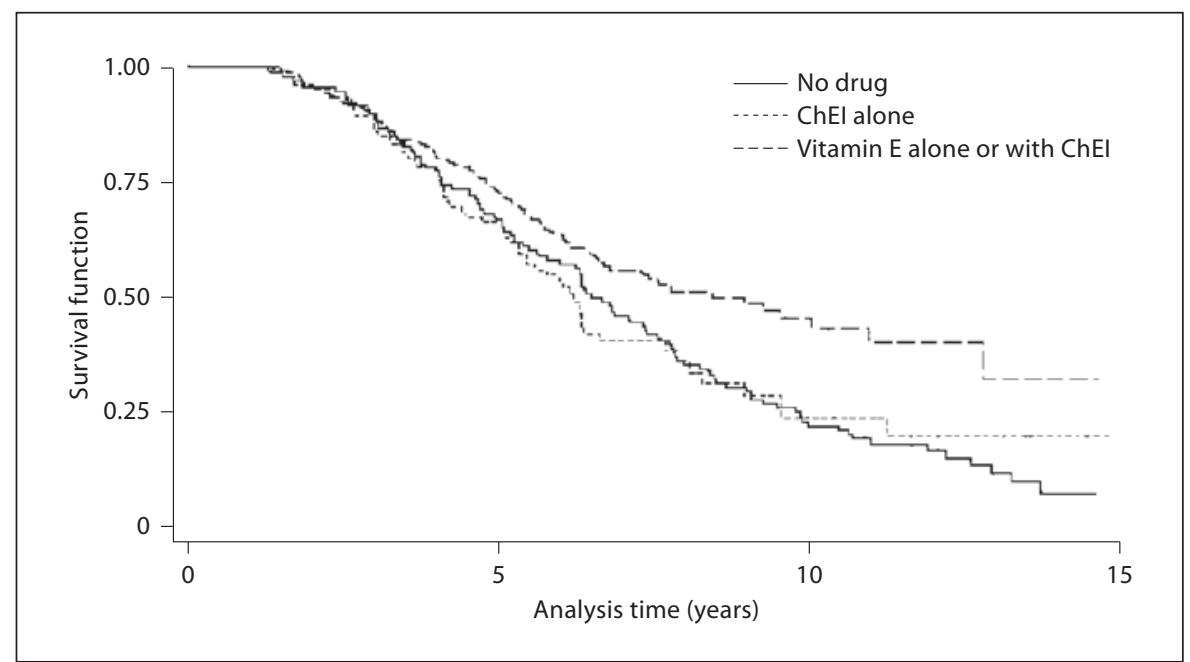

to show a benefit in those taking the supplement. The most recent negative result was announced in November 2008, when a large NIH-sponsored prostate cancer prevention trial, the Selenium and Vitamin E Cancer Prevention Trial (SELECT) [15] (http://www.crab.org/select), was stopped due to evidence of a lack of benefit with regard to the primary endpoint, accompanied by statistically nonsignificant trends toward harm (e.g. higher incidence of type 2 diabetes), among those treated with 400 IU vitamin $E$ and/or $200 \mu g$ selenium per day. The SELECT included a substudy examining the effects of vitamin $\mathrm{E}$ and selenium on the prevention of dementia, but no results from that substudy have been announced yet.

The study of vitamin $\mathrm{E}$ and selegiline to prevent progression in moderate $\mathrm{AD}$ reported by Sano et al. [6] in 1997 remains the only randomized clinical trial that supports both the safety and efficacy of high-dose vitamin E supplementation in AD. The dose of vitamin E tested in this trial was 2,000 IU per day. Of the trials included in the meta-analysis by Miller et al. [9], only one other, in a Parkinson's disease population, tested a dose as high as 2,000 IU per day. The trend toward a dose-related increase in mortality with higher doses of vitamin E led Miller et al. [9] to advise against a supplementation with more than $400 \mathrm{IU}$ per day.

Roberts et al. [16] argued that little was known about dose-dependent effects of vitamin $\mathrm{E}$ on the suppression of oxidative stress and conducted a dosing and time course study on individuals with elevated plasma cholesterol. They found that the peak reduction of oxidative stress, as measured by plasma $\mathrm{F}_{2}$-isoprostane, did not occur until week 16 of the supplementation with $3,200 \mathrm{IU}$
Table 3. Cox's survival analysis for different exposure categories

\begin{tabular}{|c|c|c|c|}
\hline & HR & $95 \% \mathrm{CI}$ & $\mathrm{p}$ \\
\hline \multicolumn{4}{|c|}{ Vitamin E regimens versus all other categories $(n=764)$} \\
\hline Age & 1.03 & $1.02-1.05$ & $<0.001$ \\
\hline Sex $(1=$ male; $0=$ female $)$ & 1.90 & $1.52-2.37$ & $<0.001$ \\
\hline \multicolumn{4}{|l|}{ Race $(1$ = white; } \\
\hline $0=$ other race/ethnicity) & 1.81 & $1.25-2.62$ & 0.002 \\
\hline \multicolumn{4}{|l|}{ Baseline severity } \\
\hline Moderate vs. severe & 0.86 & $0.63-1.19$ & 0.376 \\
\hline Mild vs. severe & 0.52 & $0.37-0.72$ & $<0.001$ \\
\hline Vitamin E regimen & 0.71 & $0.57-0.89$ & 0.003 \\
\hline \multicolumn{4}{|c|}{ Vitamin E regimens and non-vitamin-E regimens versus no drug } \\
\hline Age & 1.03 & $1.02-1.05$ & $<0.001$ \\
\hline Sex $(1=$ male; $0=$ female $)$ & 1.93 & $1.54-2.42$ & $<0.001$ \\
\hline \multicolumn{4}{|l|}{ Race (1 = white; } \\
\hline $0=$ other race/ethnicity) & 1.83 & $1.26-2.65$ & 0.001 \\
\hline \multicolumn{4}{|l|}{ Baseline severity } \\
\hline Moderate vs. severe & 0.84 & $0.61-1.67$ & 0.300 \\
\hline Mild vs. severe & 0.50 & $0.36-0.70$ & $<0.001$ \\
\hline \multicolumn{4}{|l|}{ Drug regimen } \\
\hline $\begin{array}{l}\text { Vitamin } \mathrm{E} \text { (alone or with other } \\
\text { antidementia drug) vs. no drug }\end{array}$ & 0.77 & $0.60-1.00$ & 0.051 \\
\hline ChEI without vitamin E vs. no drug & 1.20 & $0.87-1.6$ & 0.273 \\
\hline
\end{tabular}

The duration of symptoms, education and CVD was nonsignificant $(\mathrm{p}>0.20)$ in all models (HR not shown).

per day, and that a significant reduction in $\mathrm{F}_{2}$-isoprostane levels did not occur with doses less than 1,600 IU per day. These authors concluded that the results of both observational and experimental studies on vitamin E effects were difficult to interpret because of the lack of documenta- 
tion of the relationship between vitamin $\mathrm{E}$ dosage and change in oxidative stress.

Patients in most clinical treatment trials are followed up for less than 5 years. The fact that the survival curves in our $\mathrm{AD}$ cohort did not begin to diverge until after 4 years of follow-up raises the possibility that the benefits of vitamin $\mathrm{E}$ supplementation are difficult to observe under the constraints of a randomized trial. Another factor that must be considered in evaluating the results is that only $6 \%$ of the patients in our AD cohort had features of concurrent cerebrovascular disease, and the population is thus quite different from that included in trials that have evaluated vitamin E supplementation to prevent cardiovascular and cerebrovascular outcomes. We adjusted for the presence of CVD in our analysis, but the number of patients with this feature was too small to be analyzed separately.

The results of our observational study in an $\mathrm{AD}$ cohort are not consistent with a harmful effect of vitamin $\mathrm{E}$ on overall survival. In light of the potential for beneficial effects and mixed clinical trial evidence, they emphasize the need for additional research on vitamin E supplementation in $\mathrm{AD}$ using a dose range that extends above 400 IU per day.

The strength of our study is that it includes a large number of $\mathrm{AD}$ patients followed up over a relatively long period of time with a standardized documentation of medication history and outcomes. In addition, the study reflects the outcomes of actual clinical practice in $\mathrm{AD}$ treatment.

The findings of the study must be interpreted with caution in view of its observational nature. The numbers of patients grouped in the different medication exposure categories were not equal, and selection factors associated with long-term drug exposure cannot be ruled out as alternative explanations for the findings.

\section{Acknowledgment}

Until 2000, this patient cohort was, in part, supported by an NIH grant (AGO-8664), and from 2002 to 2004, by a Zenith Award from the Alzheimer's Association.

\section{References}

1 Engelhart MJ, Geerlings MI, Ruitenberg A, et al: Dietary intake of antioxidants and risk of Alzheimer disease. JAMA 2002;287:32233229.

2 Engelhart MJ, Ruitenberg A, Meijer J, et al: Plasma levels of antioxidants are not associated with Alzheimer's disease or cognitive decline. Dement Geriatr Cogn Disord 2005; 19:134-139.

-3 Zandi PP, Anthony JC, Khachaturian AS, et al: Reduced risk of Alzheimer disease in users of antioxidant vitamin supplements: the Cache County Study. Arch Neurol 2004;61: 82-88.

-4 Laurin D, Masaki KH, Foley DJ, White LR, Launer LJ: Midlife dietary intake of antioxidants and risk of late-life incident dementia: the Honolulu-Asia Aging Study. Am J Epidemiol 2004;159:959-967.

-5 Cherubini A, Martin A, Andres-Lacueva C, et al: Vitamin E levels, cognitive impairment and dementia in older persons: the InCHIANTI study. Neurobiol Aging 2005;26:987994.
-6 Sano M, Ernesto C, Thomas RG, et al: A controlled trial of selegiline, alpha-tocopherol, or both as treatment for Alzheimer's disease: the Alzheimer's Disease Cooperative Study. N Engl J Med 1997;336:1216-1222.

7 Petersen RC, Thomas RG, Grundman M, et al: Vitamin E and donepezil for the treatment of mild cognitive impairment. N Engl J Med 2005;352:2379-2388.

-8 Vivekananthan DP, Penn MS, Sapp SK, Hsu A, Topol EJ: Use of antioxidant vitamins for the prevention of cardiovascular disease: meta-analysis of randomised trials. Lancet 2003;361:2017-2023.

9 Miller ER 3rd, Pastor-Barriuso R, Dalal D, Riemersma RA, Appel LJ, Guallar E: Metaanalysis: high-dosage vitamin E supplementation may increase all-cause mortality. Ann Intern Med 2005;142:37-46.

10 Bjelakovic G, Nikolova D, Gluud LL, Simonetti RG, Gluud C: Mortality in randomized trials of antioxidant supplements for primary and secondary prevention: systematic review and meta-analysis. JAMA 2007; 297:842-857.

- 11 McKhann G, Drachman D, Folstein M, Katzman R, Price D, Stadlan EM: Clinical diagnosis of Alzheimer's disease: report of the NINCDS-ADRDA Work Group under the auspices of Department of Health and $\mathrm{Hu}$ man Services Task Force on Alzheimer's Disease. Neurology 1984;34:939-944.
12 Doody R, Pavlik V, Massman P, et al: Changing patient characteristics and survival experience in an Alzheimer's center patient cohort. Dement Geriatr Cogn Disord 2005;20: 198-208.

13 Doody RS, Dunn JK, Huang E, Azher S, Kataki M: A method for estimating duration of illness in Alzheimer's disease. Dement Geriatr Cogn Disord 2004;17:1-4.

14 Folstein M, Folstein S, McHugh P: 'MiniMental State': a practical method for grading the cognitive state of patients for the clinician. J Psychiatr Res 1975;12:189-198.

15 Klein EA, Thompson IM, Lippman SM, et al: SELECT: the Selenium and Vitamin E Cancer Prevention Trial. Urol Oncol 2003;21: 59-65.

16 Roberts L, Oates J, Linton M, et al: The relationship between dose of vitamin $\mathrm{E}$ and suppression of oxidative stress in humans. Free Radic Biol Med 2007;43:1388-1393. 